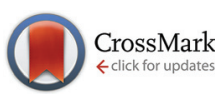

Cite this: Org. Biomol. Chem., 2016, 14,3498

Received 2nd March 2016,

Accepted 14th March 2016

DOI: $10.1039 / \mathrm{c} 6 \mathrm{ob00483k}$

www.rsc.org/obc

\section{Rapid access to unsymmetrical tolanes and alkynones by sequentially palladium-catalyzed one-pot processes $\uparrow$ t}

\author{
Alissa C. Götzinger and Thomas. J. J. Müller*
}

\begin{abstract}
Alkynones as well as unsymmetrically substituted tolanes (diarylalkynes) can be rapidly generated in a one-pot fashion via sequential palladium catalysis. Terminal alkynes, formed in situ by protecting-group free palladium-catalyzed coupling of aryl iodides with ethynyl magnesium bromide, are subsequently transformed by Sonogashira coupling with aryl halides or aroyl chlorides to furnish unsymmetrically substituted alkynes in good to excellent yields.
\end{abstract}

Unsymmetrically substituted alkynes are valuable building blocks in heterocycle synthesis ${ }^{1}$ and, in their own right, exhibit interesting properties for applications in molecular electronics. ${ }^{2}$ The most common approach to this class of molecules is the palladium-catalyzed coupling of aryl halides or aroyl chlorides with terminal alkynes, ${ }^{3}$ which are usually synthesized by Sonogashira coupling of a second aryl halide with trimethylsilyl acetylene (TMS acetylene), followed by work up, isolation, and desilylation. While several one-pot approaches to unsymmetrically substituted tolanes, i.e. diarylalkynes, are known, protected acetylene species such as TMS acetylene, ${ }^{4}$ propiolic acid, ${ }^{5}$ or methyl butynol ${ }^{6}$ are usually applied, followed by in situ deprotection and coupling. No analogous onepot synthesis of alkynone derivatives has so far been published to the best of our knowledge. We herein present a protectinggroup free, sequentially palladium-catalyzed multicomponent approach $^{7}$ towards alkynones ${ }^{8}$ and unsymmetrically substituted tolanes in a one-pot fashion.

In the conception of this novel one-pot approach we first reasoned that intermediate terminal alkynes can be generated in situ by a palladium-catalyzed Kumada-type coupling of aryl iodides with ethynyl magnesium bromide originally presented by Negishi and coworkers. ${ }^{9}$ Ethynyl magnesium bromide is a commercially available activated acetylene species and can be

Institut für Organische Chemie und Makromolekulare Chemie, Heinrich-HeineUniversität Düsseldorf, Universitätsstraße 1, D-40225 Düsseldorf, Germany. E-mail: ThomasJJ.Mueller@uni-duesseldorf.de

$\uparrow$ Dedicated to Prof. Dr Dieter Enders on the occasion of his $70^{\text {th }}$ birthday.

\$ Electronic supplementary information (ESI) available: Experimental details and NMR spectra of compounds 4, 6, and 8. See DOI: 10.1039/c6ob00483k considered as the precursor of the commonly employed TMS acetylene. Most advantageously, the reagent is easy to handle and the only side product is the corresponding magnesium halide. Therefore, a subsequent Sonogashira coupling could be concatenated in a one-pot fashion with no further addition of palladium catalyst.

Table 1 Sequentially Pd-catalyzed three-component synthesis of alkynones 4 from aryl iodides 1, ethynyl magnesium bromide (2), and aroyl chlorides 3

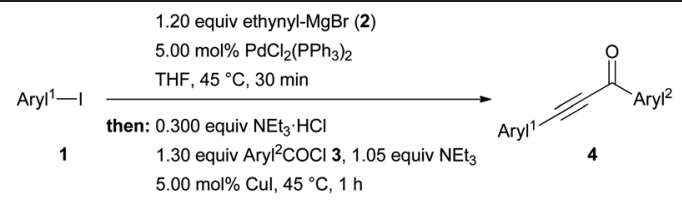

\begin{tabular}{lllll}
\hline Entry & Product & Aryl $^{1}$ & Aryl $^{2}$ & $\begin{array}{l}\text { Yield of } \\
\text { alkynone } 4(\%)\end{array}$ \\
\hline 1 & $\mathbf{4 a}$ & $4-\mathrm{MeOC}_{6} \mathrm{H}_{4}$ & $\mathrm{Ph}$ & 81 \\
2 & $\mathbf{4 b}$ & $4-\mathrm{MeOC}_{6} \mathrm{H}_{4}$ & $4-\mathrm{Tol}$ & 80 \\
3 & $\mathbf{4 c}$ & $3,4,5-\left(\mathrm{MeO}_{3} \mathrm{C}_{6} \mathrm{H}_{2}\right.$ & $\mathrm{Ph}$ & 68 \\
4 & $\mathbf{4 d}$ & $3,4,5-(\mathrm{MeO})_{3} \mathrm{C}_{6} \mathrm{H}_{2}$ & $2-\mathrm{Thienyl}$ & 76 \\
5 & $\mathbf{4 e}$ & $\mathrm{Ph}$ & $\mathrm{Ph}$ & 86 \\
6 & $\mathbf{4 f}$ & $4-\mathrm{Me}_{2} \mathrm{NC}_{6} \mathrm{H}_{4}$ & $\mathrm{Ph}$ & 79 \\
7 & $\mathbf{4 g}$ & $2-\mathrm{Naphthyl}$ & $\mathrm{Ph}$ & 82 \\
8 & $\mathbf{4 h}$ & $4-\mathrm{Me}_{2} \mathrm{NC}_{6} \mathrm{H}_{4}$ & $4-\mathrm{F}_{3} \mathrm{CC}_{6} \mathrm{H}_{4}$ & 60 \\
9 & $\mathbf{4 i}$ & $4-\mathrm{Me}_{2} \mathrm{NC}_{6} \mathrm{H}_{4}$ & $4-\mathrm{NCC}_{6} \mathrm{H}_{4}$ & 74 \\
10 & $\mathbf{4 j}$ & $\mathrm{Ph}$ & $4-\mathrm{MeOC}_{6} \mathrm{H}_{4}$ & 59
\end{tabular}

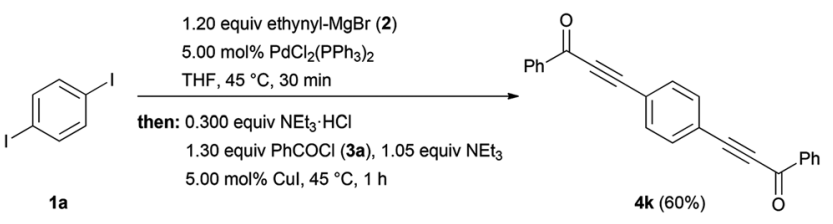

Scheme 1 Pseudo-five component synthesis of 3,3'-(1,4-phenylene)bis (1-phenylprop-2-yn-1-one) (4k) from 1,4-diiodobenzene (1a), ethynyl magnesium bromide (2), and benzoyl chloride (3a). 
Indeed, this sequentially Pd-catalyzed reaction can be performed within $2 \mathrm{~h}$ by first reacting aryl iodides 1 with ethynyl magnesium bromide (2) under modified Kumada conditions, followed by partial neutralization with substoichiometric amounts of triethylammonium chloride and coupling with aroyl chlorides 3 in the presence of catalytic amounts of CuI

Table 2 Sequentially Pd-catalyzed three-component synthesis of diarylalkynes 6 from aryl iodides 1, ethynyl magnesium bromide (2), and aryl halides 5

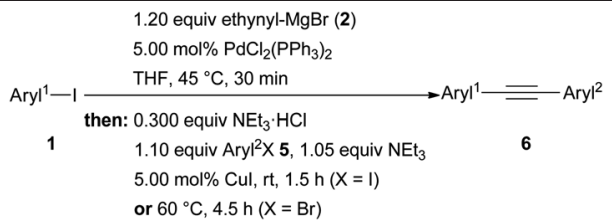

\begin{tabular}{llllll}
\hline Entry & Product & Aryl $^{1}$ & Aryl $^{2}$ & X & $\begin{array}{l}\text { Yield of } \\
\text { diarylalkyne 6 (\%) }\end{array}$ \\
\hline 1 & $\mathbf{6 a}$ & $4-\mathrm{MeOC}_{6} \mathrm{H}_{4}$ & $4-\mathrm{ClC}_{6} \mathrm{H}_{4}$ & $\mathrm{I}$ & 81 \\
2 & $\mathbf{6 b}$ & $4-\mathrm{MeOC}_{6} \mathrm{H}_{4}$ & $4-\mathrm{BrC}_{6} \mathrm{H}_{4}$ & $\mathrm{I}$ & 86 \\
3 & $\mathbf{6 c}$ & $4-\mathrm{MeOC}_{6} \mathrm{H}_{4}$ & $\mathrm{Ph}$ & $\mathrm{I}$ & 78 \\
4 & $\mathbf{6 d}$ & $\mathrm{Ph}$ & $4-\mathrm{Pyridyl}$ & $\mathrm{I}$ & 80 \\
5 & $\mathbf{6 e}$ & $4-\mathrm{Me}_{2} \mathrm{NC}_{6} \mathrm{H}_{4}$ & $4-\mathrm{F}_{3} \mathrm{CC}_{6} \mathrm{H}_{4}$ & $\mathrm{I}$ & 83 \\
6 & $\mathbf{6 f}$ & $4-\mathrm{F}_{3} \mathrm{CC}_{6} \mathrm{H}_{4}$ & $1-\mathrm{Naphthyl}$ & $\mathrm{I}$ & 66 \\
7 & $\mathbf{6 g}$ & $4-\mathrm{ClC}_{6} \mathrm{H}_{4}$ & $\mathrm{Ph}_{4}$ & $\mathrm{I}$ & 67 \\
8 & $\mathbf{6 h}$ & $4-\mathrm{MeOC}_{6} \mathrm{H}_{4}$ & $4-\mathrm{NCC}_{6} \mathrm{H}_{4}$ & $\mathrm{Br}$ & 64
\end{tabular}

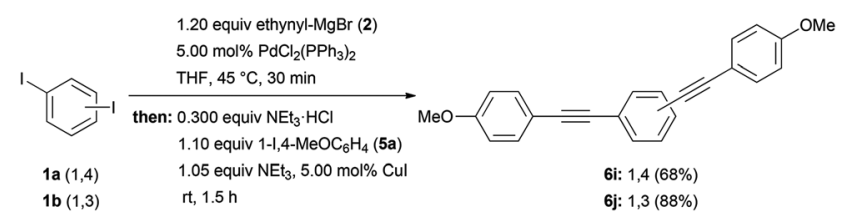

Scheme 2 Pseudo-five component synthesis of bis(arylethynyl) benzene compounds $6 \mathbf{i}$ and $\mathbf{6 j}$.

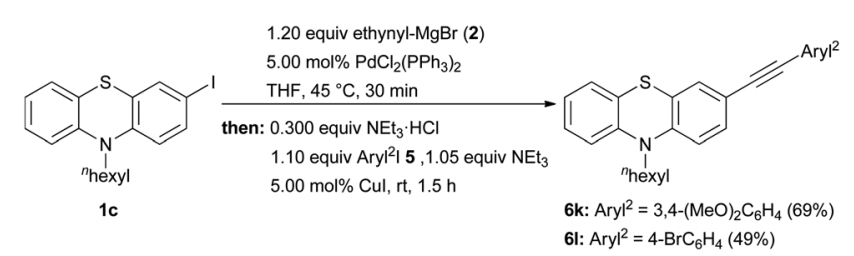

Scheme 3 Synthesis of arylethynyl phenothiazine derivatives $6 \mathrm{k}$ and $6 \mathrm{l}$. and a stoichiometric amount of triethylamine, followed by aqueous work up and simple flash chromatography. The Kumada-type alkynylation was originally performed by Negishi et al. using tetrakis(triphenyl-phosphane)palladium(0). ${ }^{9}$ This catalyst, however, gave only traces of alkynone in the subsequent Sonogashira coupling with aroyl chlorides. Changing the palladium species to bis(triphenylphosphane)palladium(II) dichloride required a slightly higher temperature for the initial alkynylation but gave good yields in the concluding alkynone formation. $^{8 a, b}$ As a result, 10 alkynones $\mathbf{4}$ were obtained in good to very good yields (Table 1 ).

A quick access is also offered to push-pull substituted derivatives $\mathbf{1} \mathbf{i}$ and $\mathbf{1} \mathbf{j}$, thus establishing a quick entry to heterocycles with interesting photophysical properties. ${ }^{10}$ By employing 1,4-diiodobenzene (1a) as aryl iodide component, bisalkynone derivative $\mathbf{4 k}$ can be easily accessed (Scheme 1).

Employing a second aryl halide $\mathbf{5}$ in the Sonogashira coupling step gives access to diarylalkynes 6 (Table 2). The Sonogashira coupling with aryl iodides $\mathbf{5 a - f}$ proceeds at room temperature within $1.5 \mathrm{~h}$. Activated aryl bromide $5 \mathrm{~g}$ bearing a cyano group can also be employed by using slightly elevated temperature and prolonged reaction time. Eight diarylalkynes 6 were synthesized by this one-pot sequence in good to excellent yields (Table 2). Upon using $\mathrm{Pd}\left(\mathrm{PPh}_{3}\right)_{4}$ as a $\mathrm{Pd}$ source, lower yields of product $6 \mathbf{a}$ (64\%) were obtained in comparison to $\mathrm{Pd}\left(\mathrm{PPh}_{3}\right)_{2} \mathrm{Cl}_{2}$ as a catalyst, which gave compound $\mathbf{6 a}$ in $81 \%$ yield (Table 2 , entry 1 ).

By employing $p$ - and $m$-diiodobenzene $\mathbf{1 a}$ and $\mathbf{1 b}$ as starting materials, the corresponding bis(arylethynyl)benzene derivatives $2 \mathbf{i}$ and $2 \mathbf{j}$ are easily accessible (Scheme 2) via a pseudofive component reaction with a respective yield of $91 \%$ and $97 \%$ per bond formation. These types of conjugated oligo(phenyleneethynylenes) are of potential interest as molecular wires ${ }^{11}$ or in the preparation of cruciform fluorophores. ${ }^{12}$

In addition, arylethynyl phenothiazine derivatives $\mathbf{2 k}$ and $\mathbf{2 l}$ can be readily prepared. These compounds have aroused particular interest for the corrosion protection of metal surfaces. ${ }^{13}$ It is noteworthy to mention that the pervious multi-step approach required several days for performing the concluding Sonogashira coupling. By using the Kumada-Sonogashira methodology, the overall reaction time can be shortened to two hours starting from 10-hexyl-3-iodo-10 $\mathrm{H}$-phenothiazine (Scheme 3).

Finally, an addition extension of the methodology to three Pd-catalyzed steps in a one-pot fashion is also possible. When

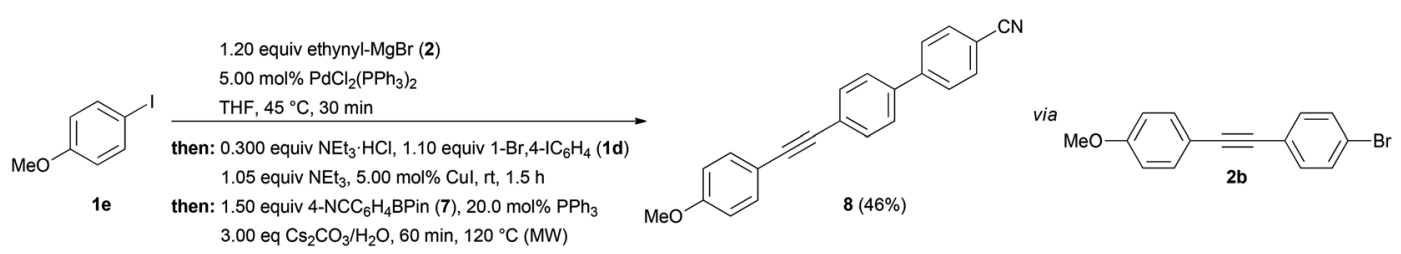

Scheme 4 Four-component synthesis of 4'-((4-methoxyphenyl)ethynyl)-[1,1'-biphenyl]-4-carbonitrile (8) by a sequentially Pd-catalyzed KumadaSonogashira-Suzuki process. 
4-bromo-1-iodobenzene (1c) is employed in the second step, the carbon-bromine bond becomes available for a concluding Pd-catalyzed Suzuki coupling with 4-cyanophenylpinacolboronic ester (7), furnishing biaryl-substituted alkyne 8 in moderate yield (Scheme 4) in the sense of a sequentially catalyzed four-component Kumada-Sonogashira-Suzuki process with $77 \%$ yield per coupling. The conditions for the terminal Suzuki coupling step were adapted from related Sonogashiracyclocondensation-Suzuki sequences. ${ }^{14}$

\section{Conclusions}

In summary, we have disclosed a convenient and versatile sequentially palladium-catalyzed synthesis of unsymmetrically substituted alkynes. The modular nature of the process, the readily available starting materials, the omission of protecting groups for the ethynyl arene formation, the mild reaction conditions, and the short reaction times open a quick and straightforward access to a large variety of disubstituted alkynes in a one-pot fashion. Moreover, the palladium catalyst is employed in a sequential fashion, catalyzing two or even three different subsequent cross-coupling reactions without any further addition. The extension of the reaction sequence to one-pot syntheses of heterocycles and further sequences is currently underway.

\section{References}

1 (a) S. R. Chemler and P. H. Fuller, Chem. Soc. Rev., 2007, 36, 1153-1160; (b) D. M. D’Souza and T. J. J. Müller, Chem. Soc. Rev., 2007, 36, 1095-1108; (c) B. Willy and T. J. J. Müller, Curr. Org. Chem., 2009, 13, 1777-1790.

2 N. Robertson and C. A. McGowan, Chem. Soc. Rev., 2003, 32, 96-103.

3 (a) E.-i. Negishi and L. Anastasia, Chem. Rev., 2003, 103, 1979-2018; (b) R. Chinchilla and C. Nájera, Chem. Rev., 2007, 107, 874-922; (c) K. Sonogashira, J. Organomet. Chem., 2002, 653, 46-49.

4 (a) P. K. Mandali and D. K. Chand, Catal. Commun., 2014, 47, 40-44; (b) M. J. Mio, L. C. Kopel, J. B. Braun, T. L. Gadzikwa, K. L. Hull, R. G. Brisbois, C. J. Markworth and P. A. Grieco, Org. Lett., 2002, 4, 3199-3202; (c) Y. Nishihara, E. Inoue, D. Ogawa, Y. Okada, S. Noyori and K. Takagi, Tetrahedron Lett., 2009, 50, 4643-4646; (d) R. Severin, J. Reimer and S. Doye, J. Org. Chem., 2010, 75, 3518-3521.

5 (a) S. Tartaggia, O. De Lucchi and L. J. Gooßen, Eur. J. Org. Chem., 2012, 1431-1438; (b) H. J. Lee, K. Park, G. Bae, J. Choe, K. H. Song and S. Lee, Tetrahedron Lett., 2011, 52, 5064-5067; (c) K. Park, W. Kim and S. Lee, Bull. Korean Chem. Soc., 2013, 34, 2859; (d) X. Li, F. Yang and Y. Wu, RSC Adv., 2014, 4, 13738-13741.

6 (a) H.-F. Chow, C.-W. Wan, K.-H. Low and Y.-Y. Yeung, J. Org. Chem., 2001, 66, 1910-1913; (b) C. Yi, R. Hua, H. Zeng and Q. Huang, Adv. Synth. Catal., 2007, 349, 1738-1742; (c) K. Xu, S. Sun, G. Zhang, F. Yang and Y. Wu, RSC Adv., 2014, 4, 32643-32646.

7 (a) T. J. J. Müller, Top. Organomet. Chem., 2006, 19, 149205; (b) T. Lessing and T. J. J. Müller, Appl. Sci., 2015, 5, 1803.

8 (a) A. S. Karpov and T. J. J. Müller, Org. Lett., 2003, 5, 34513454; (b) D. M. D’Souza and T. J. J. Müller, Nat. Protocols, 2008, 3, 1660-1665; (c) A. S. Karpov, E. Merkul, F. Rominger and T. J. J. Müller, Angew. Chem., Int. Ed., 2005, 44, 6951-6956; (d) X.-F. Wu, H. Neumann and M. Beller, Chem. Soc. Rev., 2011, 40, 4986-5009; (e) X.-F. Wu, H. Neumann and M. Beller, Angew. Chem., Int. Ed., 2011, 50, 11142-11146; (f) K. Natte, J. Chen, H. Neumann, M. Beller and X.-F. Wu, Org. Biomol. Chem., 2014, 12, 5590-5593; (g) X. Qi, L.-B. Jiang, C.-L. Li, R. Li and X.-F. Wu, Chem. - Asian J., 2015, 10, 1870-1873; (h) W. Li and X.-F. Wu, Org. Biomol. Chem., 2015, 13, 50905093.

9 E.-i. Negishi, M. Kotora and C. Xu, J. Org. Chem., 1997, 62, 8957-8960.

10 (a) B. Willy and T. J. J. Müller, Eur. J. Org. Chem., 2008, 4157-4168; (b) B. Willy and T. J. J. Müller, Org. Lett., 2011, 13, 2082-2085.

11 J. M. Tour, A. M. Rawlett, M. Kozaki, Y. Yao, R. C. Jagessar, S. M. Dirk, D. W. Price, M. A. Reed, C.-W. Zhou, J. Chen, W. Wang and I. Campbell, Chem. - Eur. J., 2001, 7, 51185134.

12 A. J. Zucchero, P. L. McGrier and U. H. F. Bunz, Acc. Chem. Res., 2010, 43, 397-408.

13 J. Rechmann, A. Sarfraz, A. C. Götzinger, E. Dirksen, T. J. J. Müller and A. Erbe, Langmuir, 2015, 31, 73067316.

14 M. Denißen, J. Nordmann, J. Dziambor, B. Mayer, W. Frank and T. J. J. Müller, RSC Adv., 2015, 5, 33838-33854. 